\title{
Two-year outcomes of pro re nata ranibizumab monotherapy for exudative age-related macular degeneration in Japanese patients
}

This article was published in the following Dove Press journal:

Clinical Ophthalmology

I8 April 2013

Number of times this article has been viewed

\section{Akiko Yamamoto' \\ Annabelle A Okada' \\ Atsuhiko Sugitani ${ }^{1,2}$ \\ Daisuke Kunita' \\ Tosho Rii' \\ Reiji Yokota' \\ 'Department of Ophthalmology, Kyorin University School of Medicine, Tokyo, Japan; ${ }^{2}$ Department of Ophthalmology, Kugayama Hospital, Tokyo, Japan}

Correspondence: Annabelle A Okada Department of Ophthalmology, Kyorin University School of Medicine, 6-20-2 Shinkawa, Mitaka, Tokyo,

$|8|-86||$, Japan

$\mathrm{Tel}+8 \mathrm{I} 4224755$ II

Fax $+8 \mid 42$ 27I 6836

Email aokada@eye-center.org
Purpose: To describe outcomes of intravitreal ranibizumab using a pro re nata regimen for treatment-naive exudative age-related macular degeneration (AMD), in Japanese patients over the first 2 years.

Methods: Clinical records were retrospectively reviewed of 48 eyes of 48 patients with treatment-naive exudative AMD who underwent intravitreal ranibizumab therapy. After three monthly injections (induction), patients were examined monthly, and subsequent injections were performed as needed (pro re nata) for any residual activity, by fundus biomicroscopy and imaging studies, regardless of severity.

Results: Twenty-nine (60\%) of the patients were men, and 19 (40\%) were women; the mean age was 76.1 years. Of the 48 eyes evaluated, 17 (35\%) had findings consistent with polypoidal choroidal vasculopathy, and five $(10 \%)$ with retinal angiomatous proliferation. A mean of 6.0 ranibizumab injections were given in the first year, 3.5 in the second year, and 9.5 over the 2-year period. The best-corrected visual acuity (logarithm of minimum angle of resolution) improved significantly, from 0.35 at baseline to 0.21 at 12 months $(P<0.01)$, and remained stable at 0.21 at 24 months $(P<0.01)$. The mean central macular thickness decreased significantly, from $355.4 \mu \mathrm{m}$ at baseline to $237.9 \mu \mathrm{m}$ at $12 \mathrm{months}(P<0.01)$ and $247.7 \mu \mathrm{m}$ at 24 months $(P<0.01)$.

Conclusion: Improved visual acuity and decreased central macular thickness were observed and maintained over a 2-year period, in a Japanese population receiving 3 monthly induction injections followed by a pro re nata regimen of ranibizumab for exudative AMD.

Keywords: optical coherence tomography, polypoidal choroidal vasculopathy, retinal angiomatous proliferation

Age-related macular degeneration (AMD) is the leading cause of blindness among the elderly in most developed countries and is the fourth common cause of legal blindness for all ages in Japan. ${ }^{1}$ Ranibizumab, the recombinant, humanized antibody fragment against vascular endothelial growth factor (VEGF)-A was shown to improve mean visual acuity in eyes with exudative AMD in the MARINA and ANCHOR Phase III clinical trials, which used scheduled monthly doses.,3 However, due to the high burden associated with monthly intravitreal injections, several regimens involving less frequent dosing have been investigated, including injections every 3 months (the PIER study), ${ }^{4}$ dosing as needed or pro re nata (PRN) (the PrONTO and SUSTAIN studies), ${ }^{5-7}$ and "treat and extend" dosing. ${ }^{8,9}$ These studies were all conducted in the United States or Europe, and therefore, it is unclear whether their treatment outcomes apply to Japanese and other Asian patients with exudative AMD. 
It has been reported that $23 \%-55 \%$ of exudative AMD in Japan is due to polypoidal choroidal vasculopathy (PCV),${ }^{10-13}$ greatly exceeding those rates reported for patients in the United States. ${ }^{14}$ Preliminary studies using anti-VEGF agents in Japanese patients have shown mixed results. One study of 47 eyes described a good response to intravitreous bevacizumab in eyes with classic choroidal neovascularization (CNV) but only limited efficacy in eyes with occult CNV. ${ }^{15}$ Other studies using bevacizumab have suggested that antiVEGF therapy was not very effective for PCV in Japanese eyes. ${ }^{13,16}$ A Phase I-II clinical trial comparing two doses of monthly administrations of ranibizumab for exudative AMD in Japan showed good clinical efficacy of both doses over 1 year. ${ }^{17}$ However, a subsequent study found that the response to ranibizumab therapy over the first 3 months was shown to be better in PCV eyes than in non-PCV eyes. ${ }^{18}$

In the current retrospective study, we describe 2-year outcomes of intravitreal ranibizumab for treatment-naive exudative AMD in Japanese patients who received three monthly injections (induction) followed by injections based on a PRN scheme.

\section{Patients and methods}

We retrospectively reviewed clinic charts of patients who underwent intravitreal ranibizumab injections (Lucentis ${ }^{\circledR}$; Novartis Pharmaceuticals Corp, Basel, Switzerland; Genentech, Inc, South San Francisco, CA, USA) for the first time between March 2009 and October 2009 for the indication of exudative AMD. Patients had to be at least 50 years of age at the first ranibizumab injection and had to be treatment-naive for inclusion in the study. During the study period, 61 patients were found to have initiated ranibizumab therapy for exudative AMD, of which 48 eyes of 48 patients were followed for at least 24 months. Monthly examinations were performed on all patients, including measurement of best-corrected visual acuity (BCVA), dilated fundus biomicroscopy, color fundus photography, and optical coherence tomography (Cirrus ${ }^{\mathrm{TM}}$, Carl Zeiss Meditec, Jena, Germany). Optical coherence tomography (OCT) was performed using the macular cube mode $(200 \times 200$ scans $)$. The initial evaluation of the eyes included fluorescein angiography (VX-10, Kowa Company, Ltd, Nagoya, Japan) and indocyanine green angiography (Heidelberg Retina Angiograph 2; Heidelberg Engineering Inc, Heidelberg, Germany).

Injections of ranibizumab $(0.5 \mathrm{mg} / 0.05 \mathrm{cc})$ were performed in the outpatient clinic, using a departmental protocol for intravitreal injections. After topical anesthesia and standard antisepsis preparation and draping, injections were performed using a 30 gauge needle, under a $5 \times$ operating microscope. Preoperative and postoperative topical antibiotic drops were used. An induction of three ranibizumab injections was performed at roughly 4 week intervals, followed by monthly examinations at which time additional injections (reinjections) were performed for one or more of the following: (1) any decrease in BCVA associated with fluid in the macula, as assessed by OCT; (2) persistence of intraretinal or subretinal fluid, by OCT, that continued to diminish with additional injections; (3) any increase in central macular thickness or macular volume, by OCT; (4) new or worsening macular hemorrhage, by fundus biomicroscopy; and (5) new-onset classic CNV, as assessed by fundus biomicroscopy and/or fluorescein angiography. All reinjections were performed on the same day after confirming the necessity of reinjection.

BCVA was measured using metric charts at a distance of 5 meters and was converted to a logarithm of the minimum angle of resolution ( $\log$ MAR) for statistical analysis. Improvement or worsening of BCVA was defined as a change of at least $0.3 \log$ MAR. The comparison of two means was performed using the paired Student's $t$-test, while the comparison of three means was performed using analysis of variance (ANOVA), as indicated. Multiple logistic regression analysis was performed to examine the possible association of baseline characteristics with visual improvement. All statistical analyses were performed using JMP ${ }^{\circledR} 10$ software (version 10.0.2; SAS Institute Inc, Cary, NC, USA). $P<0.05$ was considered statistically significant.

The study protocol followed the tenets set forth in the Declaration of Helsinki, and all patients provided written informed consent before beginning intravitreal injections of ranibizumab.

\section{Results \\ Baseline clinical characteristics}

Forty-eight eyes of 48 patients were included in this study. Twenty-nine (60\%) of the patients were men, and $19(40 \%)$ were women. Patient age ranged from 64 to 89 years, with a mean of 76.1 years. Table 1 summarizes the baseline clinical characteristics of the 48 eyes. The mean visual acuity ( $\log M A R)$ was 0.35 , and the mean central macular thickness was $355.4 \mu \mathrm{m}$. Seventeen $(35 \%)$ of the eyes had features of PCV, based on criteria previously published, ${ }^{19}$ and five eyes (10\%) had features consistent with retinal angiomatous proliferation (RAP) all with stage II lesions. ${ }^{20}$ Fluorescein angiography revealed the mean greatest linear dimension (GLD) to be $3811.5 \mu \mathrm{m}$. Lesions were subfoveal (involving the center of the fovea) in 54\% of 
Table I Baseline clinical characteristics of the exudative agerelated macular degeneration eyes

\begin{tabular}{ll}
\hline No of eyes & 48 \\
Best corrected visual acuity (logMAR) mean \pm SD & $0.35 \pm 0.35$ \\
Central macular thickness $(\mu \mathrm{m})$, mean \pm SD & $355.4 \pm 97.6$ \\
Polypoidal choroidal vasculopathy & $17(35 \%)$ \\
Retinal angiomatous proliferation & $5(10 \%)$ \\
Greatest linear dimension $(\mu \mathrm{m})$, mean \pm SD & $3811.5 \pm 1749.7$ \\
CNV type & \\
$\quad$ Predominantly classic & $12(25 \%)$ \\
$\quad$ Minimally classic & $12(25 \%)$ \\
Occult with no classic & $24(50 \%)$ \\
Lesion location & \\
$\quad$ Subfoveal & $26(54 \%)$ \\
Juxtafoveal & $22(46 \%)$ \\
\hline
\end{tabular}

Note: Percentages of the total number (48) of eyes are shown in parentheses. Abbreviations: CNV, choroidal neovascularization; logMAR, logarithm of the minimum angle of resolution; SD, standard deviation.

the eyes. Predominantly classic CNV was found in 12 eyes (25\%), minimally classic CNV in 12 eyes (25\%), and occult with no classic $\mathrm{CNV}$ in 24 eyes (50\%).

\section{Number of injections, central macular thickness, and visual acuity outcomes}

The mean number of intravitreal ranibizumab injections per eye was $6.0 \pm 2.0$ over the first 12 months, $3.5 \pm 3.4$ over the second 12 months, and $9.5 \pm 4.9$ over the 24 -month study period. Overall, the mean central macular thickness decreased significantly, from $355.4 \pm 97.6 \mu \mathrm{m}$ (range 151 to $475 \mu \mathrm{m}$ ) at baseline to $237.9 \pm 67.4 \mu \mathrm{m}$ (range 134 to $434 \mu \mathrm{m})$ at 12 months $(P<0.01)$ and $247.7 \pm 82.5 \mu \mathrm{m}$ (range 110 to $430 \mu \mathrm{m})$ at 24 months $(P<0.01)$. The mean BCVA (logMAR) improved significantly, from $0.35 \pm 0.35$ (range -0.08 to 1.15 ) at baseline to $0.21 \pm 0.28$ (range -0.08 to 1.10$)$ at 12 months $(P<0.01)$, and this was maintained at $0.21 \pm 0.28$ (range -0.08 to 1.00 ) at 24 months $(P<0.01$ ).

\section{Lesion size analysis}

As shown in Figure 1, when the eyes were analyzed according to lesion size, the mean BCVA improved best in the eyes with a lesion GLD of $3000 \mu \mathrm{m}$ or less $(n=16)$, with statistically significant improvement over baseline at 3 months $(P<0.01), 6$ months $(P<0.01), 12$ months $(P<0.01)$, and 24 months $(P<0.01)$. The eyes with a lesion GLD of 3001 to $4500 \mu \mathrm{m}$ showed a statistically significant improvement over baseline at 3 months $(P=0.04)$, but significance was lost at 6 months $(P=0.66), 12$ months $(P=0.13)$, and 24 months $(P=0.36)$. The eyes with a lesion GLD greater than $4500 \mu \mathrm{m}$ showed no improvement in BCVA. The mean number of ranibizumab injections over the 24-month period was 7.4 for the eyes with a lesion GLD $\leq 3000 \mu \mathrm{m}, 10.3$ for the eyes with a lesion

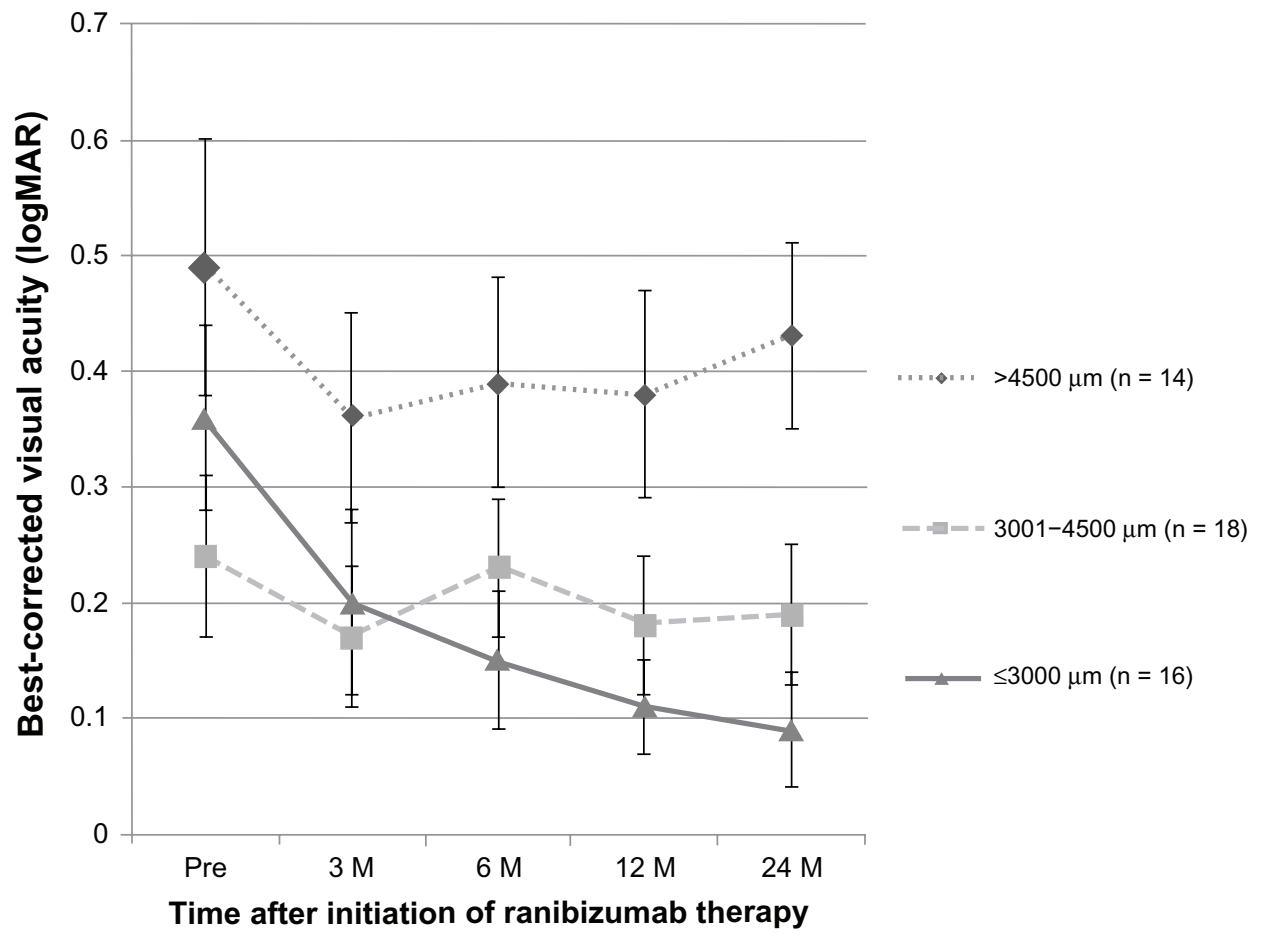

Figure I Visual acuity outcomes based on greatest linear dimension.

Note: Mean best corrected visual acuities are expressed as logMAR units.

Abbreviations: logMAR, logarithm of the minimum angle of resolution; M, months. 
GLD 3001 to $4500 \mu \mathrm{m}$, and 10.8 for the eyes with a lesion GLD $>4500 \mu \mathrm{m}$. Although there was a trend for fewer injections in the eyes with a lesion GLD $\leq 3000 \mu \mathrm{m}$, the differences were not statistically significant by ANOVA.

\section{Lesion composition analysis}

Table 2 shows the change in BCVA according to the lesion composition. Among the eyes with predominantly classic CNV, the mean BCVA improved from 0.42 at baseline to $0.11(P<0.01)$ at 24 months. For the eyes with minimally classic CNV, the mean BCVA improved from 0.56 at baseline to 0.37 at 24 months $(P=0.02)$. For the eyes with occult with no classic CNV, there was no statistically significant improvement between the mean BCVA of 0.22 at baseline and the mean BCVA of 0.19 at 24 months $(P=0.50)$. Overall, more ranibizumab injections were administered in the eyes with a greater proportion of occult CNV. The mean number of ranibizumab injections over the 24-month period was 5.5 for the eyes with predominantly classic CNV, 9.6 for the eyes with minimally classic CNV, and 11.4 for the eyes with occult with no classic CNV; the difference was statistically significant only between the eyes with predominantly classic $\mathrm{CNV}$ and the eyes with occult with no classic $\mathrm{CNV}(P<0.01)$.

\section{Analysis based on PCV and RAP features}

Table 3 shows the change in BCVA according to the type of exudative AMD, whether consistent with PCV or RAP, or lacking the features of either (termed typical AMD). Among the eyes with typical AMD, the mean BCVA improved from 0.43 at baseline to 0.23 at 24 months $(P<0.01)$. Among the eyes with PCV, the mean BCVA improved from 0.26 at baseline to 0.19 at 24 months; this improvement was statistically significant until month 16 (data not shown), but significance was lost thereafter. Examination of the data showed that only two of the 17 PCV eyes had a greater than $0.3 \log$ MAR worsening of BCVA. Of these two eyes, one eye had undergone 13 injections over 18 months, with visual improvement to 1.0; however, 2 months after the 13th injection, the BCVA worsened to 0.2 , and this was attributed to the onset of a hemorrhagic retinal pigment epithelium tear. The one other PCV eye with poor visual outcome had worsening of hemorrhage despite six injections over the first 6 months, with the BCVA dropping from 0.9 to 0.5 .

For the eyes with RAP, the mean BCVA was 0.27 at baseline and 0.17 at 24 months; this difference was not statistically significant compared with baseline. There was no difference in the mean number of injections administered over the 24 months in the eyes with typical AMD (9.1 injections) versus that in eyes with PCV (9.9 injections) or RAP (9.8 injections). Specifically among the 17 PCV eyes, the mean number of injections was 5.4 in the first year and 4.2 in the second year.

\section{Baseline factors predictive of visual improvement}

In order to examine whether baseline clinical characteristics were predictive of visual improvement $( \pm 0.3 \log M A R)$, multiple logistic regression analysis was performed. As shown in Table 4, this confirmed that a smaller lesion GLD was, indeed, independently associated with visual improvement. Furthermore, younger patient age and better initial BCVA were identified to be independently predictive of visual improvement.

\section{Complications}

No injection-related complications, such as endophthalmitis or retinal detachment, were observed during the study period. In addition, there were no reports of stroke or other thromboembolic events.

\section{Discussion}

In summary, the present study of Japanese patients with exudative AMD treated by intravitreal ranibizumab monotherapy revealed that three monthly induction injections followed by monthly examinations and a PRN regimen for subsequent injections

Table 2 Change in best corrected visual acuity, according to lesion composition a,b

\begin{tabular}{|c|c|c|c|c|c|}
\hline & Baseline & 3 months & 6 months & 12 months & 24 months \\
\hline Predominantly classic CNV & 0.42 & 0.29 & 0.25 & 0.17 & 0.11 \\
\hline$(n=12)$ & & $P<0.01$ & $P=0.02$ & $P<0.0 \mathrm{I}$ & $P<0.01$ \\
\hline Minimally classic CNV & 0.56 & 0.40 & 0.42 & 0.40 & 0.37 \\
\hline$(n=12)$ & & $P<0.01$ & $P=0.02$ & $P=0.05$ & $P=0.02$ \\
\hline Occult with no classic CNV & 0.22 & 0.13 & 0.16 & 0.14 & 0.19 \\
\hline$(n=24)$ & & $P<0.01$ & $P=0.12$ & $P=0.04$ & $P=0.50$ \\
\hline
\end{tabular}

Notes: ${ }^{a}$ Best corrected visual acuities are expressed as logarithm of the minimum angle of resolution; ${ }^{b}$ all $P$-values are in comparison with baseline. Abbreviation: CNV, choroidal neovascularization. 
Table 3 Change in best corrected visual acuity, according to type of exudative age-related macular degeneration ${ }^{\mathrm{a}, \mathrm{b}}$

\begin{tabular}{|c|c|c|c|c|c|}
\hline & Baseline & 3 months & 6 months & 12 months & 24 months \\
\hline Typical age-related macular degeneration & 0.43 & 0.28 & 0.30 & 0.25 & 0.23 \\
\hline$(n=26)$ & & $P<0.01$ & $P<0.01$ & $P<0.01$ & $P<0.01$ \\
\hline Polypoidal choroidal vasculopathy & 0.26 & 0.18 & 0.17 & 0.14 & 0.19 \\
\hline$(n=17)$ & & $P=0.01$ & $P=0.03$ & $P=0.04$ & $P=0.31$ \\
\hline Retinal angiomatous proliferation & 0.27 & 0.19 & 0.12 & 0.15 & 0.17 \\
\hline$(n=5)$ & & $P=0.31$ & $P=0.81$ & $P=0.38$ & $P=0.44$ \\
\hline
\end{tabular}

Notes: aBest corrected visual acuities are expressed as logarithm of the minimum angle of resolution; ball $P$-values are in comparison with baseline.

resulted in significantly improved visual acuity by the end of the first year that was maintained at the end of the second year. The improved visual acuity corresponded to a decrease in central macular thickness that also remained stable through the second year. As one would expect, the eyes with smaller lesions had the best visual acuity improvement and a trend towards the least number of injections; smaller-lesion GLD was confirmed to be an independent factor associated with visual improvement. Furthermore, the eyes with predominantly classic $\mathrm{CNV}$ and minimally classic CNV both obtained significant improvements in visual acuity, but this was not so for the eyes with occult with no classic CNV. The eyes with typical AMD showed improvement in mean visual acuity at 2 years, while the PCV and RAP eyes showed an initial visual improvement that was subsequently lost by the end of 2 years.

Although a direct comparison with the two major studies of induction followed by a PRN regimen (PrONTO and SUSTAIN) is difficult, due to differences in the measurement of visual acuity, the different criteria for reinjection, the different OCT equipment used (higher-resolution spectral domain OCT in the present study, as opposed to the lowerresolution time domain OCT in most previous studies), and the fact that a lower dose $(0.3 \mathrm{mg})$ was used initially in the

Table 4 Multiple logistic regression analysis of baseline characteristics possibly associated with visual improvement ${ }^{\mathrm{a}}$

\begin{tabular}{|c|c|c|c|}
\hline & Odds ratio & $\begin{array}{l}95 \% \text { confidence } \\
\text { interval }\end{array}$ & $P$-value \\
\hline Age & 0.786 & $0.559-0.993$ & 0.043 \\
\hline Male gender & 1.064 & $0.067-21.101$ & 0.965 \\
\hline Baseline BCVA & $1.431 \times 10^{6}$ & $6.849 \times 10^{2}-1.070 \times 10^{12}$ & $<0.001$ \\
\hline $\begin{array}{l}\text { Central macular } \\
\text { thickness }\end{array}$ & 1.001 & $0.990-1.016$ & 0.874 \\
\hline $\begin{array}{l}\text { Greatest linear } \\
\text { dimension }\end{array}$ & 0.837 & $0.679-0.948$ & 0.001 \\
\hline $\begin{array}{l}\text { Presence of classic } \\
\mathrm{CNV}\end{array}$ & 0.306 & $0.021-2.997$ & 0.316 \\
\hline Subfoveal location & 3.748 & $0.292-82.747$ & 0.315 \\
\hline
\end{tabular}

Note: ${ }^{\vee}$ isual improvement was defined as a 24-month BCVA improvement of $\geq 0.3$ logMAR over baseline.

Abbreviations: BCVA, best corrected visual acuity; CNV, choroida neovascularization; logMAR, logarithm of the minimum angle of resolution.
SUSTAIN study, our results in Japanese patients showed an overall similar improvement in visual acuity and decrease in central macular thickness..$^{5-7}$ In our patients, a slightly lower mean number of injections were performed compared with patients in the PrONTO study (9.5 injections over 2 years in the present study versus 9.9 injections over 2 years in the PrONTO study), while a slightly greater mean number of injections were performed compared with those in the SUSTAIN study (6.0 injections over 1 year in the present study versus 5.7 injections over 1 year in the SUSTAIN study). Of note, we considered any worsening of the macula, whether by visual acuity (worsening of BCVA had to be accompanied by fluid, on OCT) or by findings on OCT, fundus biomicroscopy, and/or fluorescein angiography, to be an indication for reinjection. In contrast, the reinjection criteria for PrONTO and SUSTAIN included a visual acuity reduction of at least five letters (with OCT evidence of fluid in the macula, for PrONTO) or an increase in OCT central retinal thickness of at least $100 \mu \mathrm{m}$. Furthermore, our use of spectral domain OCT may have resulted, in our study, in the detection of smaller amounts of fluid in the macula, prompting reinjections that may not have been deemed necessary had time domain OCT been used.

Our study included a fairly high proportion of PCV eyes (35\%), as one would expect for Japan. Although the percentages of eyes with PCV features were not reported for PrONTO and SUSTAIN, these studies were conducted in the US and Europe respectively, and therefore, one would expect a much lower proportion of PCV. One study by Tsujikawa et $\mathrm{al}^{16}$ on bevacizumab injected using a PRN regimen, in 17 eyes of 16 Japanese patients with PCV, revealed that visual acuity was initially improved at 3 months but then declined subsequently, such that it was unchanged at 12 months compared with baseline. We were able to achieve statistically significant improvement in visual acuity of the PCV eyes through month 16 , although this was lost at month 24 . In our study, a greater mean number of injections were given to the PCV eyes (5.4 ranibizumab injections over the first year alone) than in the Tsujikawa 
study (4.0 bevacizumab injections over a follow-up period varying from 12-30 months), suggesting that more frequent injections lead to better visual outcomes in PCV eyes.

Eyes with $\mathrm{PCV}$ features may require more intensive anti-VEGF treatment over the long term compared with eyes without PCV. In PCV eyes, the administration of ranibizumab for 3 months followed by a PRN regimen of administration over 1 year led to improved visual acuity, with a mean of 4.2 injections in Japanese patients ${ }^{21}$ and 3.3 injections in Taiwanese patients. Other studies examined the use of bevacizumab or ranibizumab in Asian PCV eyes, using a PRN regimen after photodynamic therapy (PDT) treatment, and these showed no visual improvement but did achieve reduction in macular fluid, by OCT. ${ }^{22,23}$ One study from Korea, using anti-VEGF therapy given in three monthly injections followed by a PRN regimen, also showed only visual acuity stabilization after a mean of 4.72 bevacizumab injections or a mean of 5.52 ranibizumab injections over a 1 -year period. ${ }^{24}$ In another study, comparing ranibizumab monotherapy to ranibizumab/ PDT combination therapy for PCV, the addition of PDT did not result in additional improvement over ranibizumab therapy in 1-year outcomes. ${ }^{25}$ More recently, the 6-month results from the EVEREST study, a multicenter, prospective, randomized trial of 61 PCV eyes, found significantly higher rates of polyp regression, by indocyanine green angiography assessment, at 6 months in the ranibizumab/PDT-combination and PDT-alone groups $(77.8 \%$ and $71.4 \%$, respectively) compared with the ranibizumab monotherapy group $(28.6 \%) .{ }^{26}$ However, the mean gain in visual acuity was not different in the three groups. Moreover, the proportion of eyes gaining at least 15 letters was better in the ranibizumab monotherapy group $(33.3 \%)$ than in either the ranibizumab/PDT or the PDT-alone groups (21\% and $19 \%$, respectively). ${ }^{26}$ The results of our 2 -year study, taken together with results of other groups, suggest that best visual outcomes are obtained with ranibizumab monotherapy given frequently. We acknowledge that without periodic IA assessments to examine the effect of treatment on the polypoidal lesions and branching vascular networks in the PCV eyes, we cannot delineate the exact mechanism of efficacy with ranibizumab monotherapy. However, we speculate that, had we given more reinjections to the PCV eyes in the second year, perhaps a statistically significant improvement in vision could have been maintained longer than 16 months. Longer-acting drugs (such as aflibercept) may have the potential to maintain visual improvement in these PCV eyes.

The analysis of the eyes with typical AMD also revealed good visual improvement and reduction in central macular thickness, in our study. Due to the small number, we were unable to draw a meaningful conclusion for RAP eyes. A study from Spain pointed out that differences in clinical results at 1 year depended upon the stage of RAP, with stage II eyes without pigment epithelial detachment having better outcomes compared with stage II with pigment epithelial detachment or stage III eyes. ${ }^{27}$ Interestingly, an analysis of RAP eyes in Japanese and Korean patients treated with a combination of ranibizumab and PDT suggests that, at least at the 1-year time point, mean visual acuity improved..$^{28,29}$ Therefore, RAP may be one type of exudative AMD in which the addition of PDT to anti-VEGF therapy does improve visual outcomes.

The strengths of our study included the long follow-up period of 2 years and the fairly large number of eyes examined. In addition, our study analyzed treatment in a typical clinical setting using a uniform PRN regimen in all patients. The weaknesses of our study included its retrospective nature and the absence of a comparison treatment strategy. Furthermore, during the same time period, 13 eyes that had initiated ranibizumab treatment were not analyzed for a variety of reasons that included the return of some patients to the referring ophthalmologist, transition of the patient to a different treatment strategy (bevacizumab or combined anti-VEGF and PDT treatment), or loss of the patient to follow up. We believe that the lack of inclusion of the results from these eyes could have produced either positive or negative bias to our results.

In conclusion, in Japanese eyes with exudative AMD, ranibizumab monotherapy performed as three monthly induction injections followed by a PRN regimen resulted in an improvement in mean visual acuity and a decreased mean central macular thickness, using a mean of 9.5 injections performed over a 2-year period. Smaller lesion GLD size was independently associated with visual improvement.

\section{Disclosure}

Dr Okada serves as a consultant for GlaxoSmithKline, Novartis Pharmaceutical Corporation, and XOMA, and received lecture fees from Mitsubishi Tanabe Pharma, Novartis Pharma Japan, Pfizer Japan, and Santen Pharmaceuticals. The authors report no other conflicts of interest.

\section{References}

1. Ministry of Health, Labour and Welfare of Japan. 2005 Nanchisei shikkan kokufuku kenkyu jigyou moumyakurakumaku/shishinkei ishukushou ni taisuru kenkyu. Heisei 17nendo soukatsu/buntan kenkyu houkokusho [Report of the Research Committee on Chorioretinal Degenerations and Optic Atrophy]. 2006:263-267. Japanese

2. Rosenfeld PJ, Brown DM, Heier JS, et al; MARINA Study Group. Ranibizumab for neovascular age-related degeneration. $N$ Engl J Med. 2006;355(14):1419-1431. 
3. Brown DM, Kaiser PK, Michels M, et al; ANCHOR Study Group. Ranibizumab versus verteporfin for neovascular age-related macular degeneration. N Engl J Med. 2006;355(14):1432-1444.

4. Regillo CD, Brown DM, Abraham P, et al. Randomized, double-masked, sham-controlled trial of ranibizumab for neovascular age-related macular degeneration: PIER Study year 1. Am J Ophthalmol. 2008; 145(2):239-248.

5. Fung AE, Lalwani GA, Rosenfeld PJ, et al. An optical coherence tomography-guided, variable dosing regimen with intravitreal ranibizumab (Lucentis) for neovascular age-related macular degeneration. Am J Ophthalmol. 2007;143(4):566-583.

6. Lalwani GA, Rosenfeld PJ, Fung AE, et al. A variable-dosing regimen with intravitreal ranibizumab for neovascular age-related macular degeneration: year 2 of the PrONTO Study. Am J Ophthalmol. 2009; 148(1):43-58.

7. Holz FG, Amoaku W, Donate J, et al; SUSTAIN Study Group. Safety and efficacy of a flexible dosing regimen of ranibizumab in neovascular age-related macular degeneration: the SUSTAIN study. Ophthalmology. 2011;118(4):663-671.

8. Gupta OP, Shienbaum G, Patel AH, Fecarotta C, Kaiser RS, Regillo $\mathrm{CD}$. A treat and extend regimen using ranibizumab for neovascular age-related macular degeneration: clinical and economic impact. Ophthalmology. 2010;117(11):2134-2140.

9. Oubraham H, Cohen SY, Samimi S, et al. Inject and extend dosing versus dosing as needed: a comparative retrospective study of ranibizumab in exudative age-related macular degeneration. Retina. 2011;31(1):26-30.

10. Sho K, Takahashi K, Yamada H, et al. Polypoidal choroidal vasculopathy: incidence, demographic features, and clinical characteristics. Arch Ophthalmol. 2003;121(10):1392-1396.

11. Obata R, Yanagi Y, Kami J, Takahashi H, Inoue Y, Tamaki Y. Polypoidal choroidal vasculopathy and retinochoroidal anastomosis in Japanese patients eligible for photodynamic therapy for exudative age-related macular degeneration. Jpn J Ophthlmol. 2006;50(4):354-360.

12. Maruko I, Iida T, Saito M, Nagayama D, Saito K. Clinical characteristics of exudative age-related macular degeneration in Japanese patients. Am J Ophthalmol. 2007;144(1):15-22.

13. Gomi F, Sawa M, Sakaguchi H, et al. Efficacy of intravitreal bevacizumab for polypoidal choroidal vasculopathy. Br J Ophthalmol. 2008;92(1):70-73.

14. Yannuzzi LA, Wong DW, Sforzolini BS, et al. Polypoidal choroidal vasculopathy and neovascularized age-related macular degeneration. Arch Ophthalmol. 1999;117(11):1503-1510.

15. Suzuki M, Gomi F, Sawa M, Tsujikawa M, Sakaguchi H. Bevacizumab treatment for choroidal neovascularization due to age-related macular degeneration in Japanese patients. Jpn J Ophthalmol. 2010; 54(2):124-128.

16. Tsujikawa A, Ooto S, Yamashiro K, Tamura H, Otani A, Yoshimura N. Treatment of polypoidal choroidal vasculopathy by intravitreal injection of bevacizumab. Jpn J Ophthalmol. 2010;54(4):310-319.
17. Tano Y, Ohji M; EXTEND-I Study Group. EXTEND-I: safety and efficacy of ranibizumab in Japanese patients with subfoveal choroidal neovascularization secondary to age-related macular degeneration. Acta Ophthalmol. 2010;88(3):309-316.

18. Matsumiya W, Honda S, Bessho H, Kusuhara S, Tsukahara Y, Negi A. Early responses to intravitreal ranibizumab in typical neovascular age-related macular degeneration and polypoidal choroidal vasculopathy. J Ophthalmol. 2011:742020.

19. Japanese Study Group of Polypoidal Choroidal Vasculopathy. Criteria for diagnosis of polypoidal choroidal vasculopathy. Nippon Ganka Gakkai Zasshi. 2005;109(7):417-427. Japanese.

20. Yannuzzi LA, Negrão S, Iida T, et al. Retinal angiomatous proliferation in age-related macular degeneration. Retina. 2001;21(5):416-434.

21. Hikichi T, Higuchi M, Matsushita T, et al. One-year results of three monthly ranibizumab injections and as-needed reinjections for polypoidal choroidal vasculopathy in Japanese patients. Am J Ophthalmol. 2012;154(1):117-124

22. Kim KS, Lee WK. Bevacizumab for serous changes originating from a persistent branching vascular network following photodynamic therapy for polypoidal choroidal vasculopathy. Jpn J Ophthalmol. 2011;55(4):370-377.

23. Wakabayashi T, Gomi F, Sawa M, Tsujikawa M, Nishida K. Intravitreal bevacizumab for exudative branching vascular networks in polypoidal choroidal vasculopathy. Br J Ophthalmol. 2012;96(3):394-399.

24. Cho HJ, Kim JW, Lee DW, Cho SW, Kim CG. Intravitreal bevacizumab and ranibizumab injections for patients with polypoidal choroidal vasculopathy. Eye (Lond). 2012;26(3):426-433.

25. Song MH, Ryu HW, Roh YJ. One-year results of intravitreal ranibizumab with or without photodynamic therapy for polypoidal choroidal vasculopathy. Ophthalmologica. 2011;226(3):119-126.

26. Koh A, Lee WK, Chen LJ, et al. EVEREST study: efficacy and safety of verteporfin photodynamic therapy in combination with ranibizumab or alone versus ranibizumab monotherapy in patients with symptomatic macular polypoidal choroidal vasculopathy. Retina. 2012; 32(8):1453-1464.

27. Reche-Frutos J, Calvo-Gonzalez C, Pérez-Trigo S, Fernandez-Perez C, Donate-Lopez J, Garcia Feijoo J. Ranibizumab in retinal angiomatous proliferation (RAP): influence of RAP stage on visual outcome. Eur J Ophthalmol. 2011;21(6):783-788.

28. Lee MY, Kim KS, Lee WK. Combination therapy of ranibizumab and photodynamic therapy for retinal angiomatous proliferation with serous pigment epithelial detachment in Korean patients: twelve-month results. Retina. 2011;31(1):65-73.

29. Saito M, Iida T, Kano M. Combined intravitreal ranibizumab and photodynamic therapy for retinal angiomatous proliferation. Am J Ophthalmol. 2012;153(3):504-514.
Clinical Ophthalmology

\section{Publish your work in this journal}

Clinical Ophthalmology is an international, peer-reviewed journal covering all subspecialties within ophthalmology. Key topics include: Optometry; Visual science; Pharmacology and drug therapy in eye diseases; Basic Sciences; Primary and Secondary eye care; Patient Safety and Quality of Care Improvements. This journal is indexed on Submit your manuscript here: http://www.dovepress.com/clinical-ophthalmology-journa

\section{Dovepress}

PubMed Central and CAS, and is the official journal of The Society of Clinical Ophthalmology (SCO). The manuscript management system is completely online and includes a very quick and fair peer-review system, which is all easy to use. Visit http://www.dovepress.com/ testimonials.php to read real quotes from published authors. 